\section{HONOURS AND AWARDS}

\begin{abstract}
The British Society for
Restorative Dentistry

Three prizes were awarded at this year's annual scientific meeting. Senior house officer Gareth Calvert from Newcastle Dental Hospital received the clinical prize for his case on the use of gingivally toned composite for the treatment of unsightly gingival recession.

Zahra Hussain, based at Eastman Dental Hospital, presented her MSc research on the assessment of bone volume using cone beam in patients with hypodontia which earned her the research prize. The audit prize went to Derek Hall for his project which assessed the frequency of complications with locator attachments for implant retained overdentures provided by Sheffield Dental Hospital.
\end{abstract}

\section{Award for Regenerative}

Periodontal Medicine

Professor Nikos Donos, Head and Chair of Periodontology and Director of Research at the UCL Eastman Dental Institute, received the 2011 IADR/Straumann Award for Regenerative Periodontal Medicine in recognition of his outstanding contribution to research in this specialist field. The prestigious award, worth $\$ 5,000$, was presented at the 89th General Session of the International Association for Dental Research in California in March.

\section{Lifetime achievement award}

Dr Mervyn Druian, the first UK dentist to introduce the practice of porcelain veneers almost 30 years ago, has been presented with a lifetime achievement award from the British Dental Bleaching Society (BDBS) at the World Aesthetic Congress in June. Dr Druian also introduced the first power whitening system in 1990 and was the principle dentist on television's 'Extreme Makeovers UK'.

\section{IMPLANT HEALING TIMES COULD BE CUT}

Researchers at the University of Gothenburg, Sweden, have come up with a method that could shorten the healing time for patients with titanium dental implants.

The researchers studied the surface structure of dental implants at micro level and also at nano level.

'Increasing the active surface at nano level and changing the conductivity of the implant allows us to affect the body's own biomechanics and speed up the healing of the implant, said researcher Johanna Löberg. 'This would reduce the discomfort for patients and makes for a better quality of life during the healing process.'

Titanium is covered with a thin layer of naturally formed oxide and it is this oxide's properties that determine how well an implant fuses with the bone. Anchoring the implant in the bone exerts a mechanical influence on the bone tissue and this facilitates the formation of new bone. Johanna Löberg has come up with a method that describes the implant's topography from micrometre to nanometre scale and allows theoretical estimations of anchoring in the bone by different surface topographies. The method can be

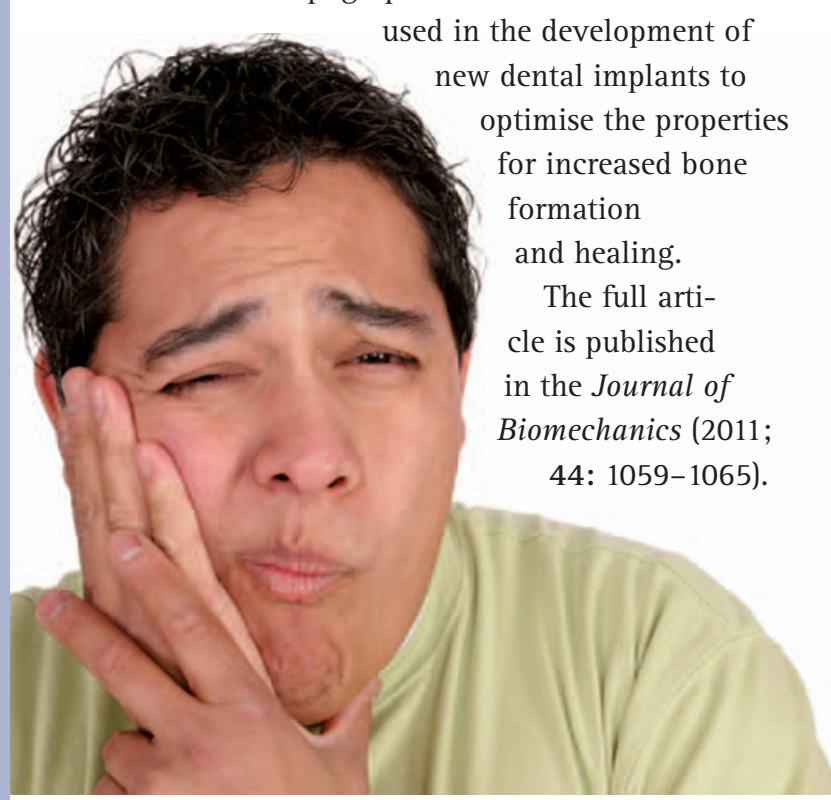

- The BDA's Training essentials team has added new courses to its portfolio. The one day courses 'Oral cancer: the dental team's responsibility' will provide five hours of verifiable $\mathrm{CPD}$ to all participants and 'Clinical photography in the dental practice' will provide five and a half hours. "The essentials of staff management: a two-day intensive course' provides new managers with the skills to succeed and will also refresh the skills of existing managers, with 11 hours of CPD. See www.bda.org/training or call 02075634590.

\section{NO MOUTHWASH-CANCER LINK FOUND}

An independent quantitative meta-analysis of epidemiological studies by the International Prevention Research Institute (iPRI) has found no statistically significant association between the use of mouthwash containing alcohol and the risk of mouth cancer.

The iPRI research team undertook a comprehensive search for published studies which had sufficient information to allow adequate estimation of the relative risk and 95\% confidence levels. Eighteen full-text articles matched the study criteria and were included in the meta-analysis. The results also revealed no significant trend in oral cancer risk with increasing daily use of mouthwash containing alcohol. 